\title{
Preparation of superhydrophobic titanium surface via the combined modification of hierarchical micro/nanopatterning and fluorination
}

\author{
Zhen Wang, Bing Ren
}

Received: 29 November 2020 / Revised: 16 October 2021/ Accepted: 19 October 2021

(C) The Author(s) 2022

\begin{abstract}
Adhesion of bacteria and platelets on blood-contact implants and surgical devices is one of the causes of infections and thrombus. A superhydrophobic surface serving as a protective layer can minimize adhesion and contamination due to the low surface energy. The objective of this paper is to construct a superhydrophobic surface on a titanium implant by a combination of a topological structure and chemical coating. First, a micro/nano hierarchical morphology is obtained by sandblasting, acid-etching, and anodic oxidation. Then, a low surface energy coating material (fluoroalkylsilane, as the example case in this study) is used to modify the surface further. The effects of the morphology of micro and/or nanoscales and corresponding fluorination on the wettability are investigated. The results show that a hierarchical
\end{abstract}

surface with microroughness and nanotubes is successfully constructed, and the contact angle (CA) is $44.9^{\circ}$, indicating good hydrophilicity. Interestingly, after being modified by fluoroalkylsilane, the surface converted from hydrophilic to superhydrophobic with a CA of $151.4^{\circ}$. In contrast, the fluorination modification of single micro or nanofeatures cannot achieve superhydrophobicity, indicating that the micro/nanostructures may show a synergistic effect for an efficient fluorination coating later on. Overall, our results demonstrate the feasibility of achieving a superhydrophobic surface via the micro/nano topological patterning and fluorination modification. The proposed method is expected to enrich the preparation technologies of superhydrophobic titanium surfaces.

Z. Wang $(\bowtie)$

School of Management Science and Engineering, Shandong University of Finance and Economics, Jinan 250061, China

e-mail: wangzhen@sdufe.edu.cn

B. Ren

Key Laboratory of High Efficiency and Clean

Manufacturing, School of Mechanical Engineering,

Shandong University, Jinan 250061, China

e-mail: renbingsdu@163.com 


\section{Graphic abstract}

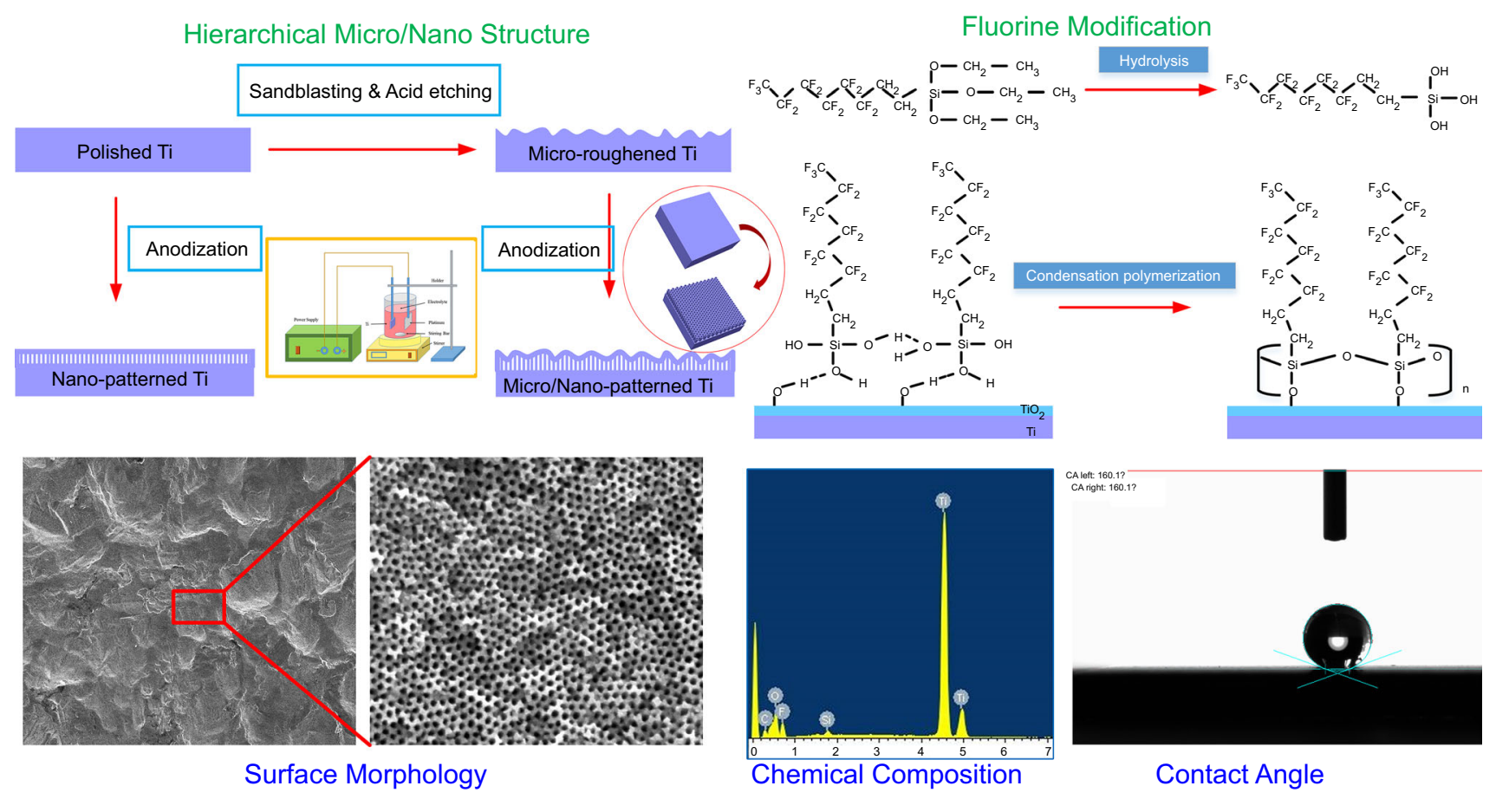

Keywords Superhydrophobic surface, Titanium, Wettability, Surface modification,

Micro/nanoengineering

\section{Introduction}

Preparation technology of superhydrophobic surfaces has been inspired by various objects in nature like lotus leaves, cicada wings, and rice foliage, which have unique wettability with water contact angles (CA) above $150^{\circ} .{ }^{1-4}$ Many special functions of these surfaces, such as low adhesion, reduced drag, and self-cleaning, have been found to be attributed to the superhydrophobicity. ${ }^{2,5,6}$ Therefore, the preparation of superhydrophobic surfaces has attracted considerable attention for the promising application in pipeline protection, ${ }^{7}$ shipbuilding, ${ }^{8}$ and biomedical instruments. ${ }^{9}$ It has been reported that superhydrophobicity can be achieved by increasing the surface roughness and reducing the surface energy. ${ }^{10-12}$ The fabrication of superhydrophobic surfaces on various materials has been extensively studied, such as on silicon ${ }^{13}$ stainless steel, ${ }^{14}$ and aluminum alloy. ${ }^{15}$

Due to the superior biocompatibility and mechanical strength, Ti and its alloys are the most widely used materials for biomedical implants and surgical devices. ${ }^{16,17}$ However, infections and thrombosis associated with the adhesion of bacteria and platelets remain as the greatest challenges for the long-term success of blood-contact implants, such as prosthetic heart valves

and vascular stents. Thrombotic occlusion of the stented vessel segment can lead to in-stent restenosis, which is one of the implantation's major failures and highly risky to the patients. ${ }^{18,19}$ As a result, surface modification is essential to improve the antithrombogenic properties by creating a protective layer at the interface. ${ }^{20}$ It has been reported that superhydrophobic surfaces can be utilized to improve blood compatibility and anticoagulation performance, ${ }^{21,22}$ and reduce the adhesion of bacteria, thus minimizing the risk of implant-associated infections. ${ }^{23}$ Therefore, the preparation of superhydrophobic Ti surfaces is essential for further biomedical applications in the future.

By mimicking the surface textures of a lotus leaf, Fadeeva et al. ${ }^{24}$ fabricated two-tier micro/nanostructures on Ti surfaces by femtosecond laser ablation, and the surface showed superhydrophobic character with a water contact angle of $166^{\circ} \pm 4^{\circ}$. Pseudomonas aeruginosa cells were found unable to attach to the surface. In another work, the femtosecond laser ablation technology was also reported to construct a micro/nanoscale hierarchical $\mathrm{TiO}_{2}$ layer and achieve a switchable underwater superoleophobicity and superoleophilicity. ${ }^{25}$ In a previous work, ${ }^{12}$ we reported a micromilling technology to fabricate parallel microgrooves on a flat Ti surface. However, it's a tedious process with a limited ability to free-form machining surfaces. Due to the poor machinability of $\mathrm{Ti}$, sandblasting and acid-etching have been widely used to construct the microfeatures. ${ }^{1,26}$ Anodic oxidation $^{27,28}$ has also been reported to create a nanotube layer on the Ti surface. The combined surface 


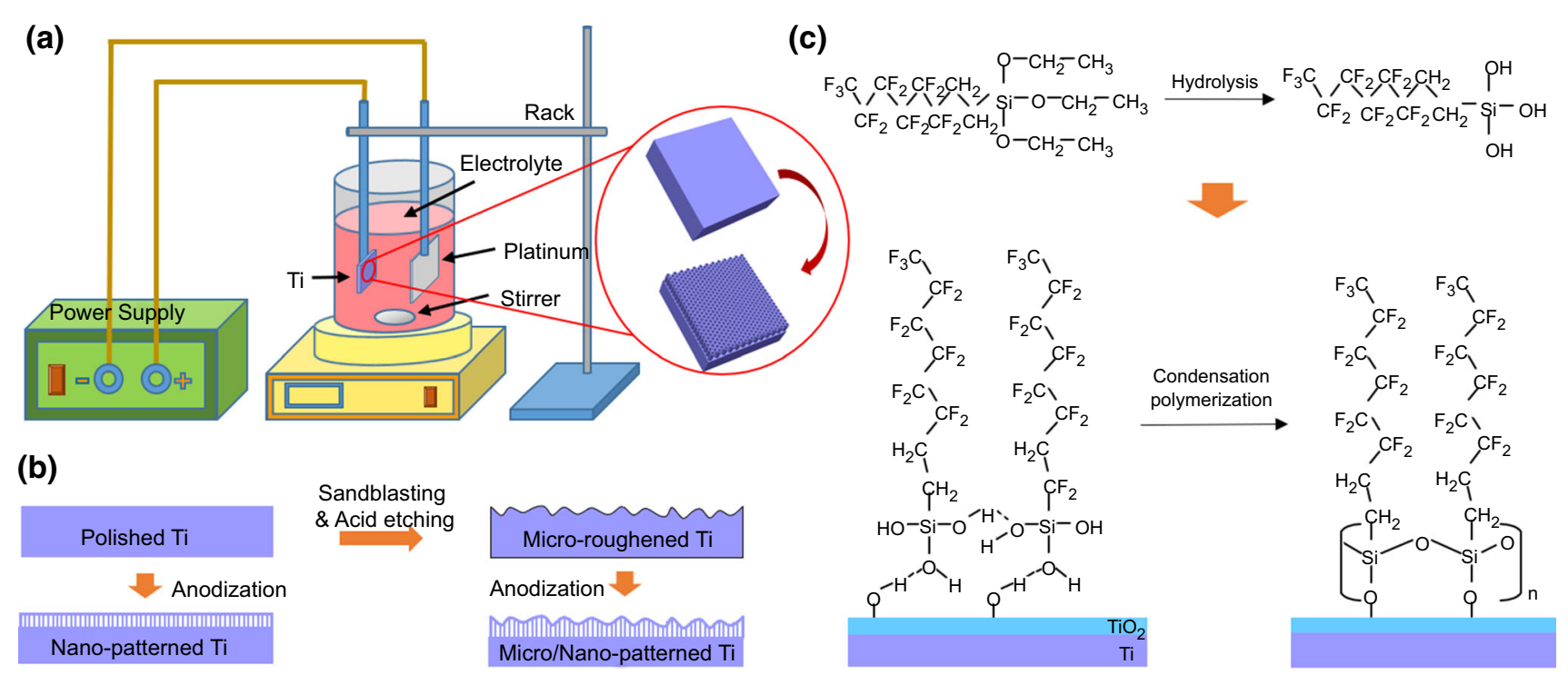

Fig. 1: (a) Schematic of the preparation processes of the four Ti groups in this study. (b) Schematic of the experimental setup for anodic oxidization. (c) Schematic of the chemical grafting process of FAS-13 onto Ti surface

modification method shows advantages in processing complex structures such as curved surfaces and internal constructions. It is also cost-efficient and suitable for large batch production.

In this study, instead of focusing on typical protrusive structures, a nanotubular structure is constructed onto the microrough substrate, and the effects of fluorination modification and wettability are further investigated. Previously, we have fabricated hierarchically structured surfaces with microroughness and nanotubes on Ti bone implants via sandblasting, acidetching, and anodic oxidation to improve the bioactivity and osseointegration. ${ }^{26,29}$ In this study, we further explore the feasibility of this micro/nanostructure on the construction of superhydrophobic surfaces. After the fabrication of this micro/nanostructure, fluoroalkylsilane modification was applied to reduce the surface energy, and the effects of morphologies under different scales on the fluorination efficiency were investigated.

\section{Materials and methods}

\section{Anodic oxidation parameter settings}

Ti6Al4V (TC4, Baoji Titanium Industry, Shaanxi, China) sheets with a dimension of $10 \mathrm{~mm} \times 10 \mathrm{~mm} \times$ $1 \mathrm{~mm}$ were successively polished with 400\#, 800\#, $1200 \#$, and 2000\# water abrasive paper on a polishing machine (Mopao1000, Shandong, China) to obtain a smooth and flat surface. Then, a polishing cloth was used to polish the surface bright. The polished samples were sequentially placed into acetone, absolute ethanol, and deionized water for ultrasonic cleaning for $15 \mathrm{~min}$ to remove surface dirt and dried for anodic oxidation. Ti sheets were linked to the anode, while a platinum electrode with a dimension of $20 \mathrm{~mm} \times 20$ $\mathrm{mm} \times 0.1 \mathrm{~mm}$ was used as the cathode. A magnetic stirrer was used to stir the electrolyte at a constant speed. The anode and the cathode were placed parallelly with a distance of $40 \mathrm{~mm}$, and the oxidation time was set as $1 \mathrm{~h}$. A schematic of the anodic oxidation is shown in Fig. 1a.

Effects of electrolytes and voltage were investigated to explore the anodic oxidation parameters. Four solutions including $0.5 \mathrm{wt} \% \mathrm{HF}$ aqueous solution, 0.25 wt. $\% \mathrm{NH}_{4} \mathrm{~F}$ aqueous solution, $1 \mathrm{~mol} / \mathrm{L} \quad \mathrm{Na}_{2} \mathrm{SO}_{4}$ solution containing 0.25 wt. $\% \mathrm{NH}_{4} \mathrm{~F}$ (using $\mathrm{H}_{2} \mathrm{SO}_{4}$ to adjust the $\mathrm{pH}$ to 3 ), ethylene glycol solution containing 0.25 wt. $\% \mathrm{NH}_{4} \mathrm{~F}$ and 2.0 wt. $\%$ deionized water, and different voltages $(10 \mathrm{~V}, 15 \mathrm{~V}, 20 \mathrm{~V}, 25 \mathrm{~V}, 30 \mathrm{~V})$ were investigated. After treatment, the processed samples were cleaned with deionized water and dried for characterization.

\section{Construction of micro/nano hierarchical structures}

Pure Ti sheets (TA2, Baoji Titanium Industry, Shaanxi, China) with dimensions of $10 \mathrm{~mm} \times 10 \mathrm{~mm} \times 1 \mathrm{~mm}$ were pretreated by polishing as described in the previous section. To create microscale structures, the samples were treated by sandblasting with $\mathrm{Al}_{2} \mathrm{O}_{3}$ particles (dimensions of $125-150 \mu \mathrm{m}$ ) at the distance of $10 \mathrm{~cm}$ under the pressure of $0.34 \mathrm{MPa}$ for $20 \mathrm{~s}$, followed by etching in a mixed acid of $\mathrm{HCl}$ and $\mathrm{HF}$.

Self-assembly nanotubes arrays were fabricated by anodic oxidation. A solution of ethylene glycol containing 0.25 wt. $\% \mathrm{NH}_{4} \mathrm{~F}$ and $2.0 \mathrm{wt}$ \% deionized water was selected as the final electrolyte, while the voltage was set as $15 \mathrm{~V}$. After $1 \mathrm{~h}$ of oxidation, specimens were rinsed with deionized water and dried for further use. Anodic oxidation was conducted to polished Ti surface and microstructured surface. As such, four groups of $\mathrm{Ti}$ 

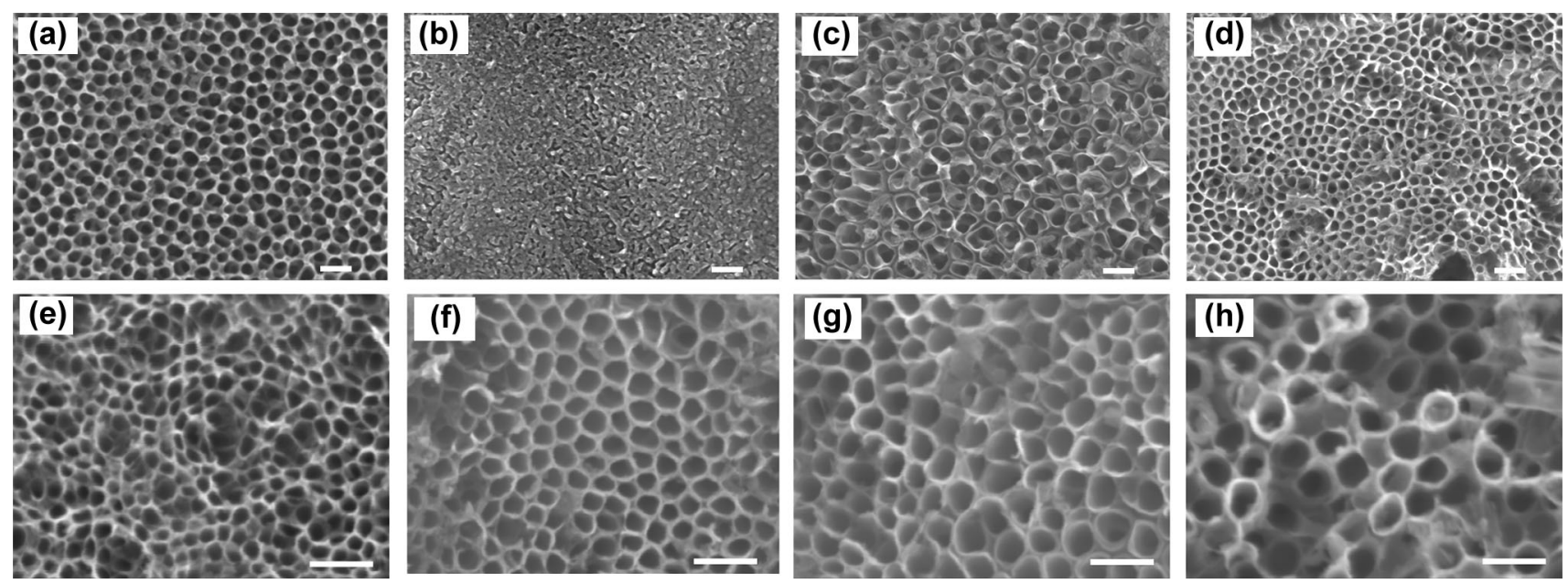

Fig. 2: Effects of anodic oxidation electrolyte and voltage on the Ti surface morphology. (a-d) Anodized surface morphology in different electrolytes: (a) 0.5 wt.\% $\mathrm{HF}$ aqueous solution, (b) $0.25 \mathrm{wt} \% \mathrm{NH}_{4} \mathrm{~F}$ aqueous solution, (c) 1 mol/ $\mathrm{Na}_{2} \mathrm{SO}_{4}$ solution containing 0.25 wt. $\% \mathrm{NH}_{4} \mathrm{~F}$ (use $\mathrm{H}_{2} \mathrm{SO}_{4}$ to adjust the $\mathrm{pH}$ to 3 ), and (d) ethylene glycol solution containing 0.25 wt. $\% \mathrm{NH}_{4} \mathrm{~F}$ and 2.0 wt.\% water. (e-h) Anodized surface morphology in ethylene glycol solution of 0.25 wt.\% $\mathrm{NH}_{4} \mathrm{~F}$ and 2.0 wt. \% water at different voltages: (e) $10 \mathrm{~V}$, (f) $15 \mathrm{~V}$, (g) $20 \mathrm{~V}$, and (h) $30 \mathrm{~V}$ (Scale bar: $100 \mu \mathrm{m}$ )

samples were obtained in this study, including polished surface, microstructured surface, nanostructured surface, and micro/nanostructured surface (Fig. 1b).

\section{Fluoroalkylsilane (FAS) modification}

To obtain the superhydrophobic surface, FAS was used to decrease the surface free energy. The specimens were immersed in a $1.0 \mathrm{wt} . \%$ ethanol solution of $1 \mathrm{H}$, $1 \mathrm{H}, 2 \mathrm{H}, 2 \mathrm{H}$-perfluorooctyl-triethoxysilane (FAS-13, $\left.\mathrm{C}_{8} \mathrm{~F}_{13} \mathrm{H}_{4} \mathrm{Si}\left(\mathrm{OCH}_{2} \mathrm{CH}_{3}\right)_{3}\right)$ at room temperature for $1 \mathrm{~h}$ and then heated at $80^{\circ} \mathrm{C}$ for $1 \mathrm{~h}$. Figure $1 \mathrm{c}$ shows a schematic of FAS molecules after hydrolysis reaction bonding onto the $\mathrm{Ti}$ substrate via covalent linkages, followed by condensation polymerization between the hydroxyl and silanol groups to form a self-assembled monolayer on the surface.

\section{Surface characterization}

The surface morphologies of the specimens were characterized by scanning electron microscope (SEM, SUPRATM55 SAPPHIRE, Carl Zeiss, Germany). Chemical composition changes of the fluorinated surfaces were investigated by energy-dispersive spectroscopy (EDS) equipped on the SEM. Three-dimensional (3D) profiles were characterized by a 3D laser scanning microscope (LSM, VK-X200K, Japan), and 3D surface parameters, including surface roughness (Sa) and developed surface area ratio (Sdr), were measured at the same time. The CAs were measured using the sessile-drop method by a contact angle goniometer (OCA15EC, Dataphysics, Germany). The volume of each water droplet was set as $2 \mu \mathrm{L}$. At least five measurements were carried out for every group of specimens.

\section{Results}

\section{Effects of electrolyte and voltage during anodic oxidation}

\section{Electrolyte}

Figures $2 a, 2 b, 2 c$ and $2 d$ show the surface morphology of the $\mathrm{Ti}$ sheets after anodic oxidation at $15 \mathrm{~V}$ for 1 hour in different electrolytes. It could be found in the 0.5 wt. \% HF aqueous solution, a layer of porous nanomesh was formed on the surface of titanium, with pore sizes ranging from 20 to $80 \mathrm{~nm}$ (Fig. 2a). In 0.25 wt. \% $\mathrm{NH}_{4} \mathrm{~F}$ solution, no tubular structure was observed (Fig. 2b). In a solution of $1 \mathrm{~mol} / \mathrm{L} \mathrm{Na}_{2} \mathrm{SO}_{4}$ solution containing $0.25 \mathrm{wt} . \% \mathrm{NH}_{4} \mathrm{~F}$ (Fig. $2 \mathrm{c}$ ), a closely arranged tubular structure was formed on the surface of the titanium. The tube diameter was $50-100 \mathrm{~nm}$, and the tube spacing was $10-20 \mathrm{~nm}$. In the ethylene glycol solution containing $0.25 \mathrm{wt} \% \quad \mathrm{NH}_{4} \mathrm{~F}$ and $2.0 \mathrm{wt} . \%$ deionized water (Fig. 2d), a uniform and ordered nanotube structure was formed on the surface of the titanium. Compared with the structure formed in the solution of 0.25 wt. $\% \mathrm{NH}_{4} \mathrm{~F}$ and $1 \mathrm{~mol} / \mathrm{L} \mathrm{Na}_{2} \mathrm{SO}_{4}$, the nanotubes were more compact with a higher circularity. The diameter of the tubes was about $40 \mathrm{~nm}$.

\section{Voltage}

In order to study the effect of voltage on the morphology of the formed nanotubes, different voltage 

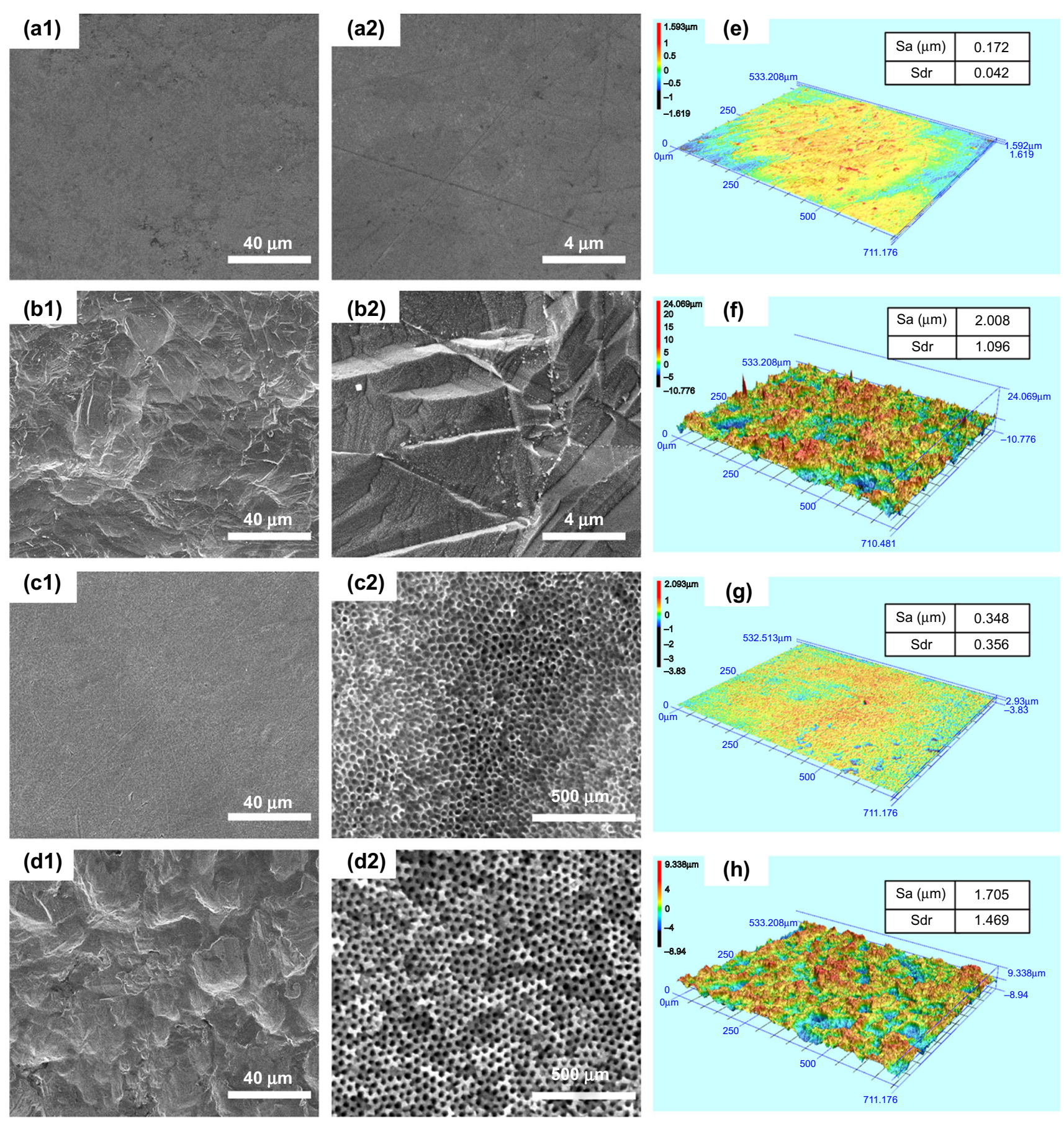

Fig. 3: SEM images at low and high magnification of different Ti surfaces without fluorination: (a1, a2) polished Ti; (b1, b2) microroughened $\mathrm{Ti}$; $(\mathrm{c1}, \mathrm{c2})$ nanopatterned $\mathrm{Ti}$; (d1, d2) micro/nanopatterned $\mathrm{Ti}$. (e-h) 3D surface profiles with Sa and Sdr values measured

settings $(10,15,20$, and $30 \mathrm{~V})$ were carried out in an ethylene glycol solution of 0.25 wt. $\% \quad \mathrm{NH}_{4} \mathrm{~F}$ and $2.0 \mathrm{wt} . \%$ water for $1 \mathrm{~h}$, and the difference in tube diameter was compared. The result is shown in Figs. 2e and $2 \mathrm{f}$. At $10 \mathrm{~V}$, the tube diameter was about $25 \mathrm{~nm}$ with poor circularity. At $15 \mathrm{~V}$, the tube diameter increased to $40 \mathrm{~nm}$, while at $30 \mathrm{~V}$, the diameter was as high as $60 \mathrm{~nm}$. With the increase of the voltage, the diameter of the nanotubes and the tube wall thickness also increased.

\section{Surface morphology}

In order to verify the effects of micro/nanoscale structures of $\mathrm{Ti}$ on the surface wettability, surface 

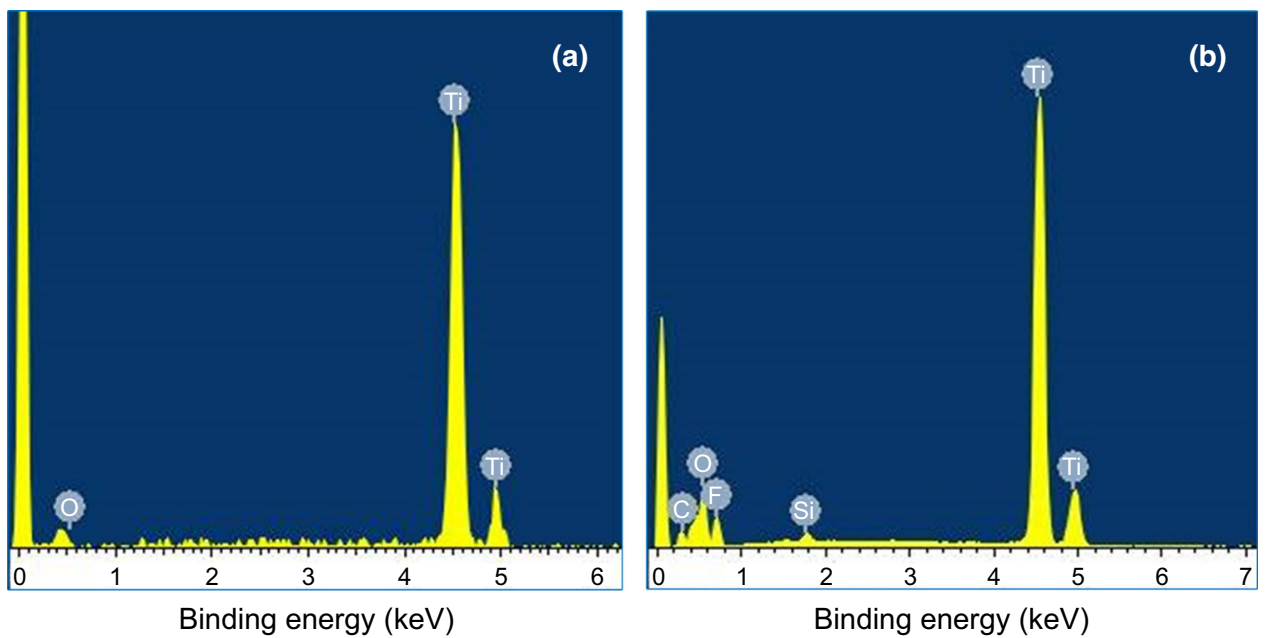

Fig. 4: EDS spectra of the micro/nanopatterned Ti surface

(a) before FAS modification and (b) after FAS modification

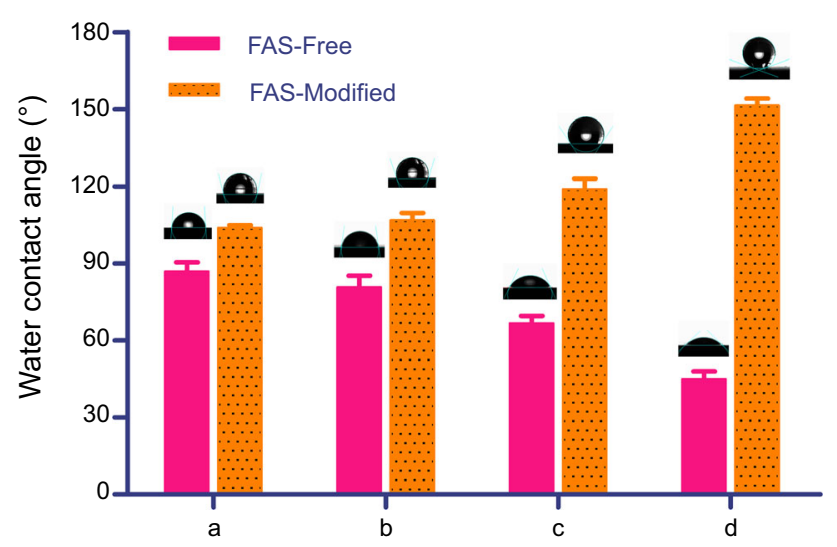

Fig. 5: CAs of different surfaces: (a) polished $\mathrm{Ti}$, (b) microroughened $\mathrm{Ti}, \quad$ (c) nanopatterned $\mathrm{Ti}, \quad$ (d) micro/nanopatterned $\mathrm{Ti}$

morphologies and 3D profiles of different groups were investigated via SEM and LSM before fluorination. As shown in Figs. 3a1 and 3a2, the surface of polished $\mathrm{Ti}$ was smooth and flat. After being processed by sandblasting and acid-etching, the surface was roughened with many micropits (Figs. $3 \mathrm{~b} 1$ and 3b2). The magnification image shows the valley-like structures located in the microcavities. In Figs. $3 c$ and $3 d$, closely arranged nanotubes resulting from anodic oxidation were found on the polished $\mathrm{Ti}$ and microroughened surfaces. The inner diameter was about 35-45 nm (Figs. 3c2 and 3d2). Slight differences can be found between the nanopatterned $\mathrm{Ti}$ and micro/nanopatterned $\mathrm{Ti}$ as the nanomorphology in Fig. $3 \mathrm{~d} 2$ was superimposed onto the microroughened surface, thus presenting a hierarchical structure.

3D profiles of Ti substrates were observed by LSM (Figs. $3 \mathrm{e}$ and $3 \mathrm{~h}$ ) with $\mathrm{Sa}$ and $\mathrm{Sdr}$ measured. $\mathrm{Sa}$ is defined as the arithmetic mean height of the surface, which gives the difference in the height of each point compared to the mean height. Sdr refers to the developed interfacial area ratio, which is expressed as the percentage of the additional surface area contributed by the fabricated surface texture compared to the planar definition area. Typically, a rougher surface leads to larger Sa and Sdr values. The measured Sa and $\mathrm{Sdr}$ values are shown in Fig. 3. No significant difference was found in terms of the 3D profiles between the polished Ti (Fig. 3e) and nanopatterned Ti (Fig. 3h), presenting relatively low $\mathrm{Sa}$ values of $0.172 \mu \mathrm{m}$ and $0.348 \mu \mathrm{m}$, respectively, compared with the other two groups. However, after being treated by sandblasting and acid-etching, the surface became rougher with a Sa value of $2.008 \mu \mathrm{m}$ due to the unevenness of existing micropits and valleys. The $\mathrm{Sdr}$ value also increased significantly, indicating the enhancement of the surface area. After the microroughened $\mathrm{Ti}$ was modified by anodization, the Sa value slightly decreased due to chemical and electrochemical etching, resulting in the surface flattening. The results are coincident with the images of 3D profiles. Sharp peaks were found on the microroughened $\mathrm{Ti}$ surface, while the micro/nanopatterned Ti surface was relatively gentle. Moreover, the $\mathrm{Sdr}$ value of the micro/nanopatterned $\mathrm{Ti}$ surface was the highest due to the composite structure.

\section{Chemical composition}

After the modification of the surface morphology, FAS was used to reduce the surface free energy. Chemical compositions of the micro/nanopatterned surface before and after fluorination are shown in Fig. 4. The surface without fluorination only consists of elements $\mathrm{Ti}$ and $\mathrm{O}$. However, elements $\mathrm{F}, \mathrm{Si}$, and $\mathrm{C}$ were detected on the as-prepared surface, indicating that a FAS film was successfully formed. It has been reported that the $\mathrm{Ti}$ surface contained a large number of hydrophilic hydroxyl groups after anodization. ${ }^{30,31}$ As shown in Fig. 1c, the FAS molecules after hydrolysis reaction were supposed to be strongly anchored onto 
the morphologically modified Ti substrate via covalent linkages, followed by condensation polymerization between the hydroxyl groups and silanol groups to form a self-assembled monolayer on the surface. ${ }^{32}$

\section{Surface wettability}

To identify the effects of different surface morphologies on the subsequent fluorination process and the wettability performance, CAs of all the samples with and without FAS modification were investigated. The results are shown in Fig. 5. The surface of polished Ti was hydrophilic with a CA of $86.7^{\circ}$. After the modification of morphology, however, the hydrophilicity of the samples with different patterns was all improved with the CA decreasing. And the micro/nanopatterned surface exhibited the best hydrophilicity with a CA of $44.9^{\circ}$.

It has been widely reported that there are two kinds of wetting state of droplets on a rough solid surface, Wenzel state ${ }^{33}$ and Cassie-Baxter state ${ }^{34}$ which were developed based on Young's model ${ }^{35}$ for smooth surfaces. According to the Cassie-Baxter theory, microstructures on the surface lead to an increased CA value because air can be trapped in the gaps to form a layer of air cushion and support the water droplets. In contrast, Wenzel's theory describes that water droplets will fully infiltrate these structures and present a "pinning effect."

The micropits and valleys generated in this study were shallow and lack of deep crevices. Therefore, the structures may have difficulties trapping air when water droplets contact the surface, resulting in the Wenzel wetting state. In this case, the relationship between the apparent $\mathrm{CA}\left(\theta_{\mathrm{w}}\right)$ and the ideal CA $\left(\theta_{\text {Young }}\right)$ is as follows:

$\cos \theta_{\mathrm{w}}=r_{\mathrm{w}} \cos \theta_{\text {Young }}$

where $r_{\mathrm{w}}$ is the roughness factor, which has been defined as the ratio of the actual surface area to the projected surface area. ${ }^{36}$ For rough surfaces, $r_{\mathrm{w}}$ is always $>1$. Thus, it can be concluded from equation (1) that an original hydrophilic surface will have higher hydrophilicity after processing to improve the surface roughness under Wenzel state.

Further, $r_{\mathrm{w}}$ is challenging to determine but can be replaced by the surface roughness parameter Sdr as follows:

$r_{\mathrm{w}}=1+\mathrm{Sdr}$

According to the results of 3D surface roughness and wettability, $\mathrm{Sdr}$ of the microroughened surface was 1.096. CA of the polished surface $\left(86.7^{\circ}\right)$ can be considered as $\theta_{\text {Young. }}$. Therefore, the CA of the microroughened surface can be predicted by combining equations (1) and (2). The calculated $\theta_{\mathrm{w}}$ is $83.1^{\circ}$, which is close to the measured CA value $\left(80.7^{\circ}\right)$.

Moreover, the improvement in hydrophobicity of the microroughened surface after FAS modification was not obvious, indicating that the construction of microscale structure via sandblasting and acid-etching was not the dominating factor in the preparation of superhydrophobic surface. In contrast, the hydrophilicity of the nanopatterned surface was satisfactory. However, the hydrophobicity greatly improved after the FAS modification. This transition from hydrophilic to hydrophobic was more evident on the micro/nanopatterned surface (from $44.9^{\circ}$ to $151.4^{\circ}$ ). From the above results, it can be concluded that the physical morphology factors of superhydrophobic surface and chemical modification were not simply superimposed but mutual basis: when the morphology was not fluorination modified, the surface tended to be hydrophilic; when the surface was only fluorination modified without microstructures, the increase of hydrophobicity was limited and could not achieve superhydrophobicity. Meanwhile, the hydrophobic effect was not obvious for the independent microstructures or nanostructures treated with fluorination. While the hydrophobicity of the micro/nano hierarchical structure increased clearly after fluorination, it should be noted that the microstructure and nanostructure showed a synergistic effect.

It has been extensively studied that the hydrophilicity of the nanotubes after anodizing is mainly due to the siphon effect of the capillary ${ }^{32,37}$ and the hydrophilic hydroxyl group on the surface. ${ }^{38}$ In the process of fluorination, these hydroxyl groups were also "anchors" of the chemical binding of FAS, which enhanced the binding area and the bonding strength. The siphon effect of the capillary and the microstructures also increased the contact area of FAS in the fluorination process and enhanced the bonding reaction. As a consenquence, the micro/nanoengineered surface shows the most profound improvement in hydrophobicity after the fluorination.

\section{Conclusions and future work}

A superhydrophobic surface was successfully prepared on $\mathrm{Ti}$ substrates by the combined modification of micro/nanoengineering and fluorination. Sandblasting and acid-etching were used to develop micro valleys and pits, and anodic oxidation was used to generate ordered nanotubes. This hierarchical micro/nanostructured surface showed good hydrophilicity. However, after the self-assembly of the monolayer on the surface by FAS modification, the surface changed to superhydrophobic due to the surface energy reduction. Moreover, the effects of the morphology under different scales on the wettability before and after fluorination were investigated. The results showed that the CA of the hierarchical surface after fluorination was the 
highest in comparison with single micro or nanostructured surfaces, which was attributed to the synergistic effect of physical morphology factors and chemical modification. The proposed method for fabricating superhydrophobic Ti surfaces could be adopted for potential applications in various fields.

Future work could focus on: (1) study of the effects of alternative micro/nanofeatures (e.g., convex versus concave features) and/or fluorination materials on the surface wettability; (2) contact angles of different liquids and study the depth that each liquid penetrates within the nanotubes; (3) stability and duration characterizations; (4) interaction of pathogenic bacteria with the created superhydrophobic surface.

Acknowledgments This research was funded by "National Natural Science Foundation of China, Grant Number 51975336", "Key Basic Research Project of Natural Science Foundation of Shandong Province, Grant Number ZR2018ZB0106", and "Key Technology Research and Development Program of Shandong, Grant Number 2019JZZY010112”.

Conflict of interest The authors declare no conflict of interest.

Open Access This article is licensed under a Creative Commons Attribution 4.0 International License, which permits use, sharing, adaptation, distribution and reproduction in any medium or format, as long as you give appropriate credit to the original author(s) and the source, provide a link to the Creative Commons licence, and indicate if changes were made. The images or other third party material in this article are included in the article's Creative Commons licence, unless indicated otherwise in a credit line to the material. If material is not included in the article's Creative Commons licence and your intended use is not permitted by statutory regulation or exceeds the permitted use, you will need to obtain permission directly from the copyright holder. To view a copy of this licence, visit http://creativecommons.org/licenses/by/4.0/.

\section{References}

1. Yang, C-J, Mei, X-S, Tian, Y-L, Zhang, D-W, Li, Y, Liu, XP, "Modification of Wettability Property of Titanium by Laser Texturing." Int. J. Adv. Manuf. Technol., 87 (5-8) 1663-1670. https://doi.org/10.1007/s00170-016-8601-9 (2016)

2. Nishimoto, S, Bhushan, B, "Bioinspired Self-cleaning Surfaces with Superhydrophobicity, Superoleophobicity, and Superhydrophilicity." RSC Adv., 3 (3) 671-690. https://doi. org/10.1039/c2ra21260a (2013)

3. Dai, S, Zhang, D, Shi, Q, Han, X, Wang, S, Du, Z, "Biomimetic Fabrication and Tunable Wetting Properties of Three-Dimensional Hierarchical $\mathrm{ZnO}$ Structures by Combining Soft Lithography Templated with Lotus Leaf and Hydrothermal Treatments." CrystEngComm, 15 (27) 5417. https://doi.org/10.1039/c3ce40238j (2013)

4. Roach, P, Shirtcliffe, NJ, Newton, MI, "Progess in Superhydrophobic Surface Development." Soft Matter, 4 (2) 224240. https://doi.org/10.1039/b712575p (2008)

5. Hassan, LB, Saadi, NS, Karabacak, T, "Hierarchically Rough Superhydrophobic Copper Sheets Fabricated by a Sandblasting and Hot Water Treatment Process." Int. J. Adv. Manuf. Technol., 93 (1-4) 1107-1114. https://doi.org/10.1007/ s00170-017-0584-7 (2017)

6. Zhang, D, Wang, L, Qian, H, Li, X, "Superhydrophobic Surfaces for Corrosion Protection: A Review of Recent Progresses and Future Directions." J. Coat. Technol. Res., 13 (1) 11-29. https://doi.org/10.1007/s11998-015-9744-6 (2015)

7. Ijaola, AO, Farayibi, PK, Asmatulu, E, "Superhydrophobic Coatings for Steel Pipeline Protection in Oil and Gas Industries: A Comprehensive Review." J. Nat. Gas Sci. Eng., 83103544 (2020)

8. Ferrari, M, Benedetti, A, "Superhydrophobic Surfaces for Applications in Seawater." Adv. Colloid Interface Sci., 222 291-304 (2015)

9. Bartlet, K, Movafaghi, S, Dasi, LP, Kota, AK, Popat, KC, "Antibacterial Activity on Superhydrophobic Titania Nanotube Arrays." Colloids Surf. B Biointerfaces, 166 179-186. https://doi.org/10.1016/j.colsurfb.2018.03.019 (2018)

10. Hosseinabadi, HN, Sajjady, SA, Amini, S, "Creating Micro Textured Surfaces for the Improvement of Surface Wettability Through Ultrasonic Vibration Assisted Turning." Int. J. Adv. Manuf. Technol., 96 2825-2839. https://doi.org/10.10 07/s00170-018-1580-2 (2018)

11. Gao, X, Tong, W, Ouyang, X, Wang, X, "Facile Fabrication of a Superhydrophobic Titanium Surface with Mechanical Durability by Chemical Etching." RSC Adv., 5 (103) 8466684672. https://doi.org/10.1039/c5ra15293c (2015)

12. Zhang, X, Wan, Y, Ren, B, Wang, H, Yu, M, Liu, A, Liu, Z, "Preparation of Superhydrophobic Surface on Titanium Alloy via Micro-milling, Anodic Oxidation and Fluorination." Micromachines, 11 (3) (2020). https://doi.org/10.3390/ mi11030316

13. Ranella, A, Barberoglou, M, Bakogianni, S, Fotakis, C, Stratakis, E, "Tuning Cell Adhesion by Controlling the Roughness and Wettability of 3D Micro/Nano Silicon Structures." Acta Biomater., 6 (7) 2711-2720. https://doi.or g/10.1016/j.actbio.2010.01.016 (2010)

14. Cai, Y, Chang, W, Luo, X, Sousa, AML, Lau, KHA, Qin, Y, "Superhydrophobic Structures on 316L Stainless Steel Surfaces Machined by Nanosecond Pulsed Laser." Precis. Eng., 52 266-275. https://doi.org/10.1016/j.precisioneng.2018.01.004 (2018)

15. Yu, HD, Zhang, XR, Wan, YL, Xu, JK, Yu, ZJ, Li, YQ, "Superhydrophobic Surface Prepared by Micromilling and Grinding on Aluminium Alloy." Surf. Eng., 32 (2) 108-113. https://doi.org/10.1179/1743294414y.0000000405 (2016)

16. Geetha, M, Singh, AK, Asokamani, R, Gogia, AK, "Ti Based Biomaterials, the Ultimate Choice for Orthopaedic Implants: A Review." Prog. Mater. Sci., 54 (3) 397-425. https://doi.org/10.1016/j.pmatsci.2008.06.004 (2009)

17. Khorasani, AM, Goldberg, M, Doeven, EH, Littlefair, G, "Titanium in Biomedical Applications-Properties and Fabrication: A Review." J. Biomater. Tissue Eng., 5 (8) 593-619. https://doi.org/10.1166/jbt.2015.1361 (2015)

18. Zhang, K, Chen, JY, Qin, W, et al. "Constructing Bio-layer of Heparin and Type IV Collagen on Titanium Surface for Improving its Endothelialization and Blood Compatibility." J. Mater. Sci. Mater. Med., 27 (4) 81 (2016) 
19. Leng, YX, Wang, J, Yang, P, et al. "The Adhesion and Clinical Application of Titanium Oxide Film on a $316 \mathrm{~L}$ Vascular Stent." Surf. Coat. Technol., 363 430-435 (2019)

20. Liu, X, Chu, P, Ding, C, "Surface Modification of Titanium, Titanium Alloys, and Related Materials for Biomedical Applications." Mater. Sci. Eng. R Rep., 47 (3-4) 49-121 (2004)

21. Yang, Y, Lai, Y, Zhang, Q, Wu, K, Zhang, L, Lin, C, Tang, $\mathrm{P}$, “A Novel Electrochemical Strategy for Improving Blood Compatibility of Titanium-Based Biomaterials." Colloids Surf. B Biointerfaces, 79 (1) 309-313. https://doi.org/10.1016/ j.colsurfb.2010.04.013 (2010)

22. Jiang, JY, Xu, JL, Liu, ZH, Deng, L, Sun, B, Liu, SD, Wang, L, Liu, HY, "Preparation, Corrosion Resistance and Hemocompatibility of the Superhydrophobic $\mathrm{TiO}_{2}$ Coatings on Biomedical Ti-6Al-4V Alloys." Appl. Surf. Sci., 347 591-595. https://doi.org/10.1016/j.apsusc.2015.04.075 (2015)

23. Patil, D, Aravindan, S, Kaushal Wasson, MP, Rao, PV, "Fast Fabrication of Superhydrophobic Titanium Alloy as Antibacterial Surface Using Nanosecond Laser Texturing." J. Micro Nano-Manuf., 6 (1) 011002. https://doi.org/10.1115/ 1.4038093 (2017)

24. Fadeeva, E, Truong, VK, Stiesch, M, et al. "Bacterial Retention on Superhydrophobic Titanium Surfaces Fabricated by Femtosecond Laser Ablation." Langmuir, 27 (6) 3012-3019 (2011)

25. Yong, J, Chen, F, Yang, Q, et al. "Photoinduced Switchable Underwater Superoleophobicity-Superoleophilicity on Laser Modified Titanium Surfaces." J. Mater. Chem. A, 3 (20) 10703-10709 (2015)

26. Ren, B, Wan, Y, Wang, G, et al., "Morphologically Modified Surface with Hierarchical Micro-/Nano-Structures for Enhanced Bioactivity of Titanium Implants." J. Mater. Sci., 53 12679-12691 (2018)

27. Gao, Y, Sun, Y, Guo, D, "Facile Fabrication of Superhydrophobic Surfaces with Low Roughness on Ti-6Al-4V Substrates via Anodization." Appl. Surf. Sci., 314 754-759. https://doi.org/10.1016/j.apsusc.2014.07.059 (2014)

28. Sun, Y, Wang, L, Gao, Y, Guo, D, "Preparation of Stable Superamphiphobic Surfaces on Ti-6Al-4V Substrates by One-Step Anodization." Appl. Surf. Sci., 324 825-830. https://doi.org/10.1016/j.apsusc.2014.11.047 (2015)

29. Ren, B, Wan, Y, Liu, C, et al., "Improved Osseointegration of 3D Printed Ti-6Al-4V Implant with a Hierarchical Micro/
Nano Surface Topography: An In Vitro and In Vivo Study." Mater. Sci. Eng. C Mater. Biol. Appl., 118111505 (2021)

30. Shin, DH, Shokuhfar, T, Choi, CK, Lee, S-H, Friedrich, C, "Wettability Changes of $\mathrm{TiO}_{2}$ Nanotube Surfaces." Nanotechnology, 22 (31) 315704. https://doi.org/10.1088/0957-44 84/22/31/315704 (2011)

31. Li, BE, Li, Y, Min, Y, Hao, JZ, Liang, CY, Li, HP, Wang, GC, Liu, SM, Wang, HS, "Synergistic Effects of Hierarchical Hybrid Micro/Nanostructures on the Biological Properties of Titanium Orthopaedic Implants." RSC Adv., 5 (61) 4955249558. https://doi.org/10.1039/c5ra05821j (2015)

32. Zhang, F, Chen, S, Dong, L, Lei, Y, Liu, T, Yin, Y, "Preparation of Superhydrophobic Films on Titanium as Effective Corrosion Barriers.” Appl. Surf. Sci., 257 (7) 25872591. https://doi.org/10.1016/j.apsusc.2010.10.027 (2011)

33. Wenzel, RN, "Resistance of Solid Surfaces to Wetting by Water." Ind. Eng. Chem., 28 (8) 988-994 (1936)

34. Cassie, ABD, Baxter, S, "Wettability of Porous Surfaces." Trans. Faraday Soc., 40 546-551 (1944)

35. Young, T, "An Essay on the Cohesion of Fluids." Philos. Trans. R. Soc. Lond., 95 (1805) 65-84 (1805)

36. Rupp, F, Gittens, RA, Scheideler, L, Marmur, A, Boyan, BD, Schwartz, Z, Geis-Gerstorfer, J, "A Review on the Wettability of Dental Implant Surfaces I: Theoretical and Experimental Aspects." Acta Biomater., 10 (7) 2894-2906. https://doi.org/10.1016/j.actbio.2014.02.040 (2014)

37. Roy, P, Dey, T, Schmuki, P, "Scanning Electron Microscopy Observation of Nanoscopic Wetting of $\mathrm{TiO}_{2}$ Nanotubes and ODS Modified Nanotubes Using Ionic Liquids." Electrochem. Solid State Lett., 13 (7) E11. https://doi.org/10.114 9/1.3413928 (2010)

38. Liang, J, Song, R, Huang, Q, Yang, Y, Lin, L, Zhang, Y, Jiang, P, Duan, H, Dong, X, Lin, C, "Electrochemical Construction of a Bio-inspired Micro/Nano-Textured Structure with Cell-Sized Microhole Arrays on Biomedical Titanium to Enhance Bioactivity." Electrochim. Acta, 174 11491159. https://doi.org/10.1016/j.electacta.2015.06.100 (2015)

Publisher's Note Springer Nature remains neutral with regard to jurisdictional claims in published maps and institutional affiliations. 